\title{
Use of Atomic Force Microscope for Selection of the Best Synthetic Reverse Osmosis Membranes for Water Desalination
}

\author{
Abdel-Hameed M. El-Aassar*, Mostafa M. S. Abo El-Fadl \\ Hydro-geochemistry Department, Desert Research Center, El-Mataryia Cairo. Egypt.
}

A R T I C LE IN F O

Article history:

Received 26 December 2010

Accepted 29 December 2010

Keywords:

Cellulose acetate membrane;

Acrylic acid;

$\mathrm{TiO}_{2}$;

AFM;

Surface morphology,

RO performance.

\begin{abstract}
A B S T R A C T
Correlations between the chemical structure of some modified synthetic cellulose acetate $(\mathrm{CA})$ reverse osmosis $(\mathrm{RO})$ membranes and their surface features were investigated by Tapping Mode Atomic Force Microscopy (TM-AFM). Also, the roughness parameters, pore and grain analyses of the obtained AFM images were estimated using Scanning Probe Image Processor (SPIP) program.

The membrane modifications included; polyethylene glycol (PEG) blending, acrylic acid (AAc) grafting and titanium dioxide $\left(\mathrm{TiO}_{2}\right)$ nanoparticles doping. The synthesized membranes were used for water desalination using three different salinities feed solutions.

By CA blending with PEG, there appeared some slight changes in the surface morphology and an increase in the roughness. By increasing the AAc grafting percent both flux and salt rejection percentages increased. AFM images showed changes in surface morphology that accompanied with an increase in roughness parameters, surface porosity and pore count of the top surface and vice versa for bottom surface. Also, the grain count decreased in the top surface as compared with the bottom surface. The increasing of $\mathrm{TiO}_{2}$ concentration resulted in an increase of flux with neglectable effect on salt rejection, all roughness parameters of top and bottom surfaces increased, while the surface porosity and the pore count decreased with high concentration of grains in the bottom layer.
\end{abstract}

\section{Introduction}

Reverse osmosis (RO) has been developed as a practical separation technology since the symmetric cellulose acetate RO membrane was developed by Loeb and Sourirajan in $1960^{1}$. Since the discovery of cellulose acetate (CA) membrane for sea water desalination, a number of materials have been tested as candidate materials for RO membranes, but still CA membranes are widely popular ${ }^{2}$. Since that time, the main emphases of RO membrane developed has been directed at improvements of RO performance, namely high salt rejection and permeate flux ${ }^{3}$.

The two mainly types of membranes suitable for membrane separation are integrally skinned membrane (asymmetric) and composite membrane ${ }^{4}$. The development of integral asymmetric membranes was a breakthrough towards the industrial application of membranes ${ }^{1}$. These membranes consist of very dense top layer or skin layer with thickness of about $0.1-0.5 \mu \mathrm{m}$ * Corresponding author.

E-mail address: hameed_m50@yahoo.com. supported by a porous sublayer with a thickness of about $50-150 \mu \mathrm{m}$.

The membranes simultaneously combine the high selectivity of a dense membrane with the high hydrophilicity and permeation capability of a very thin or porous membrane 5 .

The modification by mixture or blending with a plasticizer such as PEG was used to improve the characterization of synthetic membranes. Also, the chemical modification through the grafting with hydrophilic monomers could be employed to increase the functional groups and so improve the hydrophilicity and flux of the membrane.

It is well known that nanoparticles have unique electronic, magnetic and optical properties to improve the capabilities of polymers in a certain extent because of their small sizes, large ratio surface areas and strong activities $^{6-11}$. Among the introduced nanoparticles to polymer membranes, there is titanium dioxide $\left(\mathrm{TiO}_{2}\right)$. $\mathrm{TiO}_{2}$ nanoparticles can not only improve the hydrophilicity of membranes to enhance the flux but 
also kill bacteria and mitigate the fouling of $\mathrm{RO}$ membranes ${ }^{6,12-14}$.

Besides attempting to enhance solute rejection, solvent permeability, chemical and mechanical stability of the membranes as well as economical availability through the modification of the membranes, intensive attention was also paid to basic research on the relationship between the morphological structure and RO performance of membranes as well as to the correlation of structure with the polymeric materials and conditions of membrane preparation ${ }^{15}$.

Atomic force microscopy (AFM) is considered as one of most advanced and important means for imaging the surface of materials. It gives morphological images by scanning a sharp tip over a surface ${ }^{16-18}$. A key advantage to the technique of AFM is its ability to image nonconducting materials directly with nanometer scale resolution in air and even under liquids without special sample preparations. The technique has, therefore, attracted the interest of a number of researchers interested in the surface properties of membranes ${ }^{19-22}$. The study the surface morphology of membranes using AFM can help to elucidate and understand the correlation between the formation of membrane skin layer as well as the influence of membrane structure with its RO performance.

The aim of the present work is to study the synthesis and evaluation of the RO performance of some modified cellulose acetate (CA) membranes. The modifications include; blending with polyethylene glycol (PEG), grafting with acrylic acid (AAc) and doping with $\mathrm{TiO}_{2}$ nanoparticles by the chemically initiated procedure. Also, the application of AFM, as an important tool, was performed to clarify the relationship between the chemical structure of the synthesized membranes and both their surface morphology and RO performance.

\section{Experimental procedures}

\section{Chemicals}

Cellulose acetate (CA): Acetic acid content of 53.5$54.5 \%$, viscosity of $6 \%$ solution in $95 \%$ acetone/ water mixture at $25^{\circ} \mathrm{C}$, using a No.3 BSS viscometer 75 to 110 Cs., was supplied from $\mathrm{BDH}$. Polyethylene glycol (PEG): solid, with M.W (4000-6000) and benzoyl peroxide (BPO) was obtained from El-Gomhoryia Comp., Cairo, Egypt. Acrylic acid (AAc): purity 99.9\% (Merck, Germany) was used. Titanium dioxide nanoparticle $\left(\mathrm{TiO}_{2}\right)$ : a commercial form of $\mathrm{TiO}_{2}(\mathrm{P} 25,80 \%$ anatase, $20 \%$ rutile, BET area $50 \mathrm{~m}^{2} / \mathrm{gm}$ ) was obtained from Deggusa. The other chemicals such as solvents, inorganic salts were AR grade and used without further purification.

\section{Membranes Synthesis}

Casting solutions were freshly prepared just before use for membrane formation. The polymer (CA) was dissolved by stirring with acetone as a suitable solvent. The CA/PEG ratio was 4:1 wt.; the polymer (s) concentration was $4.74 \%$ in acetone. The mixture of copolymers solution, AAc and $\mathrm{TiO}_{2}$ nanoparticles was subjected to vigorous stirring and undergoing ultrasonic until dissolved completely and obtaining homogenous solutions, then subjected to chemical initiation. Benzoyl peroxide (BPO) was used as the initiator type in a quantity of $5 \mathrm{wt}$. \% of the monomer with gentle heating $\left(40^{\circ} \mathrm{C}\right)$ for $60 \mathrm{~min}$.

After chemical initiation of the casting solution, it was casted on a glass plate, then allowed to dry and the solvent was evaporated. The evaporation temperature was $40^{\circ} \mathrm{C}$ for $120 \mathrm{~min}$. After drying, the membrane was floated off. The thickness of the obtained synthetic membranes ranged from 150-200 $\mu \mathrm{m}$.

\section{Reverse Osmosis Performance}

Reverse osmosis properties (salt rejection and permeate flux) of the synthesized membranes were measured by laboratory DDS reverse osmosis system, model LABM20, manufactured by Alfa Laval Comp., Denmark. The salt rejection percent $\left(\mathrm{R}_{\mathrm{s}}, \%\right)$ was calculated as follows:

$$
\mathrm{R}_{\mathrm{s}}(\%)=\left(\mathrm{C}_{\mathrm{f}}-\mathrm{C}_{\mathrm{p}} / \mathrm{C}_{\mathrm{f}}\right) \times 100
$$

Where $C_{f}$ and $C_{p}$ are the concentrations of the feed and permeate water (product), respectively.

The water flux through a semi-permeable membrane is directly proportional to the pressure across the membrane and expressed as shown by Lonsdal et al., $1965^{23}$ formula: $\mathrm{J}_{\mathrm{H} 2 \mathrm{O}}=\mathrm{A}(\Delta \mathrm{P}-\Delta \Pi)$

Where; $\mathrm{J}_{\mathrm{H} 2 \mathrm{O}}$ (water flux, gm. $/ \mathrm{cm}^{2}$. sec.) is expressed in weight of the product (grams) per unit membrane area $\left(\mathrm{cm}^{2}\right)$ during operation time in sec. A is water permeability constant $\left(\mathrm{gm} / \mathrm{cm}^{2}\right.$.sec.atm), whose value depends on membrane characteristics, $\Delta \mathrm{P}$ is the differential pressure applied across the membrane and, $\Delta \Pi$ is the osmotic differential pressure (atm.) applied across the membrane.

\section{AFM Imaging}

The surface features of the synthesized membranes were observed with atomic force microscope (Veeco Instruments Nano-scope, Multimode-V5). Imaging was performed using tapping mode. The tapping mode was selected because it was appropriate for imaging the samples such as polymer that could be easily damaged by the tip. Small pieces were cut from each membrane, glued onto disks and attached to a magnetic sample holder located on top of the scanner tube. All tapping mode AFM images were undertaken at room temperature $\left(25^{\circ} \mathrm{C}\right)$.

Tapping mode operates by scanning a tip attached to the end of an oscillating cantilever across the sample surface. The cantilever is oscillated at or slightly below its resonance frequency with amplitude ranging typically from 20 to $100 \mathrm{~nm}$. The tip slightly taps on the sample surface during scanning, contacting the surface at the bottom of its swing. As the tip was scanned over the surface, the vibration amplitude of cantilever changed in response to force gradients that varied with the tip-to-sample spacing. During scanning, a laser beam is irradiated onto and reflected from the tip, and is detected by a photodiode and converted into a displayed image $^{24}$. Scanning of the synthesized membranes was 
performed in $0.3 \mathrm{~Hz}$ scanning rate with 256 pixels per line scan. The images cover an area of $5 \mu \mathrm{m} \times 5 \mu \mathrm{m}$. Since the scan area is small and not representative of the membrane, a large number of images was performed at different locations of membrane. After obtaining the images, SPIP software program was used for image analysis. The SPIP program allows quantitative determination of roughness parameters, pore and grain analysis. The roughness parameters include $R_{q}, R_{a}$ and $R_{\max }$, where $R_{q}$ is corresponding to root mean square roughness and is considered as the best roughness indicator, $R_{a}$ is the mean roughness and $R_{\max }$ is corresponding to the maximum height. The pore analysis includes the surface porosity or area coverage $(\%)$, pore radius (minimum, maximum, mean), total area of pores and pore count. The grain analysis includes the area coverage of grains (\%), grain radius (minimum, maximum, mean), total area and grain count. All work steps included the membrane synthesis, study the RO performance and AFM imaging were carried out in Desalination Unit Laboratories, Desert Research Center.

\section{Results and Discussion}

\section{Synthesis of RO membranes}

The dry casting phase inversion method was used as a technique in the membrane synthesis using the chemical initiation method. The chemical initiation method is simple and more convenient than the other methods since it involves simple equipment and inexpensive chemicals $^{25}$.

CA membrane modifications include: PEG blending, AAc grafting and $\mathrm{TiO}_{2}$ nanoparticles doping. The addition of PEG not only increases the casting solution viscosity but also lowers the solvent vapor pressure.
This leads to a lowering of the solvent evaporation rate, resulting in more residual solvent in the membrane precursor and forming more porous structure ${ }^{26}$. Moreover, AAc is used to improve the hydrophilicity of CA \& PEG copolymer membrane and facilitate the incorporation of $\mathrm{TiO}_{2}$ into the membrane matrix because of formation of coordination and hydrogen bonds between the $\mathrm{TiO}_{2}$ and carboxylic groups of AAc.

The resulted membrane thickness was measured and adjusted by controlling the amount of the casting solution. The different synthesized CA membranes and grafting with both $\mathrm{AAc}$ and $\mathrm{TiO}_{2}$ nanoparticles with various concentrations were described in Table (1).

\section{Reverse Osmosis Performance:}

After obtaining the different synthesized membranes, the performance of these membranes for water desalination process was tested using RO lab-unit. Feed solutions of three different salinities were used including; DI water, brackish and saline groundwater samples collected from Northern Coast, Egypt, with electrical conductivity (EC): $5000 \mu \mathrm{mhos} / \mathrm{cm}$, and $20000 \mu \mathrm{mhos} / \mathrm{cm}$. The desalination operation conditions were; $30 \mathrm{bar}$ as the applied pressure and $3 \mathrm{~L} / \mathrm{min}$ flow rate at room temperature. The values of both salt rejection and water flux were measured after $6 \mathrm{hrs}$. as shown in Table (2).

From the results of Table (2) it is obvious that, the synthesized reverse osmosis membranes cover a wide range of permeation and salt rejection properties; there is no any flux for both CA and CA\&PEG membranes. So, both grafting with AAc and doping with $\mathrm{TiO}_{2}$ nanoparticles were performed to enhance the RO performance.

Table 1: The different synthesized RO membranes and their compositions and thickness.

\begin{tabular}{||c||c||c||c||c||c||}
\hline No. & Polymer (s) & Solvent & $\begin{array}{c}\mathrm{AAc} \\
\text { grafting (\%) }\end{array}$ & $\begin{array}{c}\mathrm{TiO}_{2} \\
(\mathrm{wt} \%)\end{array}$ & $\begin{array}{c}\text { Thickness } \\
(\mathrm{mm})\end{array}$ \\
\hline 1 & CA $(4.74$ wt. \%) & & - & - & 0.160 \\
2 & CA\&PEG $(4.74$ wt. \%) & & - & - & 0.160 \\
3 & CA\&PEG $(4.74$ wt. \%) & Acetone & 75 & 0.5 & 0.170 \\
4 & CA\&PEG (4.74 wt. \%) & (AR) & 100 & 0.5 & 0.180 \\
5 & CA\&PEG (4.74 wt. \%) & & 125 & 0.5 & 0.190 \\
6 & CA\&PEG (4.74 wt. \%) & & 125 & 1 & 0.200 \\
\hline
\end{tabular}

Table 2: Salt rejection and water flux measurements of the synthesized membranes using different concentration feed solutions under 30 bar applied pressure, $6 \mathrm{hrs}$. operation time at room temperature.

\begin{tabular}{|c|c|c|c|c|c|c|}
\hline \multirow{2}{*}{$\begin{array}{c}\text { Membrane } \\
\text { No. }\end{array}$} & \multicolumn{2}{|c|}{ Feed Solution $1 *$} & \multicolumn{2}{|c|}{ Feed Solution 2* } & \multicolumn{2}{|c|}{ Feed Solution $3 *$} \\
\hline & $\begin{array}{c}\mathrm{J}_{\mathrm{H} 2 \mathrm{O}} \times 10^{-6} \\
\left(\mathrm{gm} / \mathrm{cm}^{2} \cdot \mathrm{sec}\right)\end{array}$ & $\begin{array}{l}\mathrm{R}_{\mathrm{S}} \\
(\%) \\
\end{array}$ & $\begin{array}{c}\mathrm{J}_{\mathrm{H} 2 \mathrm{O}} \times 10^{-6} \\
\left(\mathrm{gm} / \mathrm{cm}^{2} \cdot \mathrm{sec}\right)\end{array}$ & $\begin{array}{l}\mathrm{R}_{\mathrm{S}} \\
(\%) \\
\end{array}$ & $\begin{array}{c}\mathrm{J}_{\mathrm{H} 2 \mathrm{O}} \times 10^{-6} \\
\left(\mathrm{gm} / \mathrm{cm}^{2} \cdot \mathrm{sec}\right)\end{array}$ & $\begin{array}{l}\mathrm{R}_{\mathrm{S}} \\
(\%)\end{array}$ \\
\hline 1 & 0 & - & 0 & - & 0 & - \\
\hline 2 & 0 & - & 0 & - & 0 & - \\
\hline 3 & 8.61 & - & 7.71 & 35 & 6.94 & 32 \\
\hline 4 & 9.5 & - & 8.12 & 38 & 7.81 & 36 \\
\hline 5 & 18 & - & 14 & 42 & 12.24 & 38.3 \\
\hline 6 & 24 & - & 18.1 & 42.4 & 14.3 & 38.6 \\
\hline
\end{tabular}

*Feed solution 1: DI. Water, feed solution 2 with Ec: $5000 \mu \mathrm{mhos} / \mathrm{cm}$, feed solution 3 with Ec: $20000 \mu \mathrm{mhos} / \mathrm{cm}$. 
By increasing the AAc grafting (\%), i.e. increasing the hydrophilic groups, both permeate flux and salt rejection percents increased. The water flux increased from 7.71 to $14\left(\times 10^{-6} \mathrm{gm} / \mathrm{cm}^{2} . \mathrm{sec}\right)$ and the salt rejection increased from 35 to $42(\%)$ for brackish water feed solution. For saline water feed solution, the water flux increased from 6.94 to $12.24\left(\times 10^{-6}\right.$ $\left.\mathrm{gm} / \mathrm{cm}^{2} . \mathrm{sec}\right)$ and the salt rejection increased from 32 to $38.3(\%)$.

While, the increase of the concentration of doped $\mathrm{TiO}_{2}$ nanoparticles has an observed effect on the increase of permeate flux with a neglectable effect on salt rejection percent. The water flux increased from 14 to 18.1 $\left(\mathrm{x} 10^{-6} \mathrm{gm} / \mathrm{cm}^{2} . \mathrm{sec}\right)$ with $42-42.3(\%)$ salt rejection for brackish water feed solution. Also, for saline feed solution, the water flux increased from 12.24 to 14.3 $\left(\mathrm{x} 10^{-6} \mathrm{gm} / \mathrm{cm}^{2} . \mathrm{sec}\right)$ with $38.3-38.6(\%)$ salt rejection.

\section{AFM observations}

To explain the RO performance and investigate the correlations between the chemical structure of the synthesized RO membranes and their surface features, the changes in surface features of both top and bottom surfaces were studied using tapping mode-AFM imaging and image analysis without any flatting.

It is important to mention that, for asymmetric membrane, despite the preparation method, generally the surface morphology of the bottom (membraneglass) layer is characterized by roughness and porosity always higher than those of the top (membrane-air) layer of the dense CA membrane. In the AFM images of both bottom and top layers, one can observe the existence of large darker areas in the bottom surface. These are associated to depressions on the surface and they are generally surrounded by high elevation regions 5,27 .

Accordingly, the synthetic membranes display very different surface morphologies due to the effect of modifications as follows:

\section{The effect of PEG blending:}

To improve the properties of the prepared CA membranes, the blending of $\mathrm{CA}$ with PEG was performed. PEG is considered as one of the most useful substances that can be used as emulsifiers and plasticizers.

Figure (1) shows the micrographs of CA with and without PEG blending. For CA membrane, it is clear that, there are smooth and featureless top surface; this occurred because only acetone was used and during membrane casting the CA molecules were immobilized in a glassy state and no pores were formed ${ }^{28}$.

By blending with PEG, there are some slight changes in surface morphology and slight increasing in roughness (see $\mathrm{z}$ axis scale in the image). By image analysis using SPIP program, the roughness parameters values for CA were $\mathrm{R}_{\mathrm{q}}: 4.45 \mathrm{~nm}, \mathrm{R}_{\mathrm{a}}: 1.65 \mathrm{~nm}$ and $\mathrm{R}_{\max }: 12 \mathrm{~nm}$; these values are increased and became $R_{\mathrm{q}}: 9.3 \mathrm{~nm}, \mathrm{R}_{\mathrm{a}}: 7.2 \mathrm{~nm}$ and $\mathrm{R}_{\max }$ : $18.6 \mathrm{~nm}$ for CA\&PEG, as shown in Table (3).
So, PEG enhances the properties of CA membrane ${ }^{29,30}$. Although, there is an increase in the roughness parameters, but there is no any observed enhancement in RO performance due to the absence of active pores that corresponding to permeate flux.

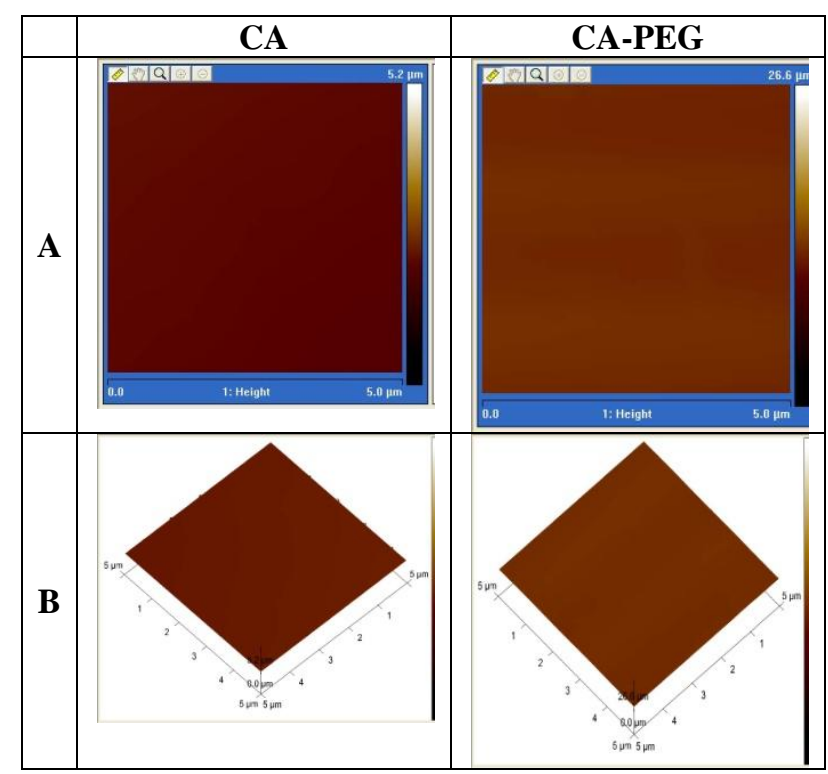

Fig. 1: AFM of CA and CA-PEG membranes (A) original image and (B) $3 \mathrm{D}$.

Table 3: Effect of CA blending with PEG on the roughness parameters of the membrane top surface.

\begin{tabular}{|c||c|c|c||}
\hline \multicolumn{1}{|c||}{$\begin{array}{c}\text { Membrane } \\
\text { No. }\end{array}$} & \multicolumn{3}{c|}{ Roughness parameter(nm) } \\
\cline { 2 - 4 } & $\mathrm{R}_{\mathrm{q}}$ & $\mathrm{R}_{\mathrm{a}}$ & $\mathrm{R}_{\max }$ \\
\hline 1 & 4.54 & 1.65 & 12 \\
\hline 2 & 9.3 & 7.2 & 18.6 \\
\hline
\end{tabular}

\section{The effect of acrylic acid grafting:}

To improve the hydrophilicity and the RO performance of the synthesized CA\&PEG copolymer membrane, attempts were carried out to graft hydrophilic vinyl monomer such as acrylic acid (AAc) onto the CA\&PEG copolymer using dry casting method with chemical initiation technique.

By the modification using different AAc grafting \%, with the same $\mathrm{TiO}_{2}$ nanoparticles concentration $(0.5 \mathrm{wt}$ $\%$ ), interesting differences were observed between both top (active layer) and bottom (support layer) surfaces of the synthesized membranes, as shown in Fig. (2). Using the images analysis, the effect of AAc grafting (\%) on roughness parameters and both pore and grain analysis was illustrated in Tables (4-6).

Table 4: Effect of AAc grafting (\%) on the roughness parameters of membrane surfaces.

\begin{tabular}{||c||c|c|c||c|c|c||}
\hline \multicolumn{1}{||c||}{$\begin{array}{c}\text { Membrane } \\
\text { No. }\end{array}$} & \multicolumn{3}{c||}{ Top Surface } & \multicolumn{3}{c||}{ Bottom surface } \\
\cline { 2 - 7 } & $\mathrm{R}_{\mathrm{q}}$ & $\mathrm{R}_{\mathrm{a}}$ & $\mathrm{R}_{\max }$ & $\mathrm{R}_{\mathrm{q}}$ & $\mathrm{R}_{\mathrm{a}}$ & $\mathrm{R}_{\max }$ \\
\hline 3 & 14.4 & 12.2 & 79.2 & 83 & 71 & 409 \\
\hline 4 & 20.1 & 14 & 189 & 52.7 & 42.7 & 282 \\
\hline 5 & 25.4 & 20.2 & 174 & 19.6 & 14.9 & 156 \\
\hline
\end{tabular}

$\mathrm{R}_{\mathrm{q}}, \mathrm{R}_{\mathrm{a}}$ and $\mathrm{R}_{\max }$ unit is $\mathrm{nm}$ 


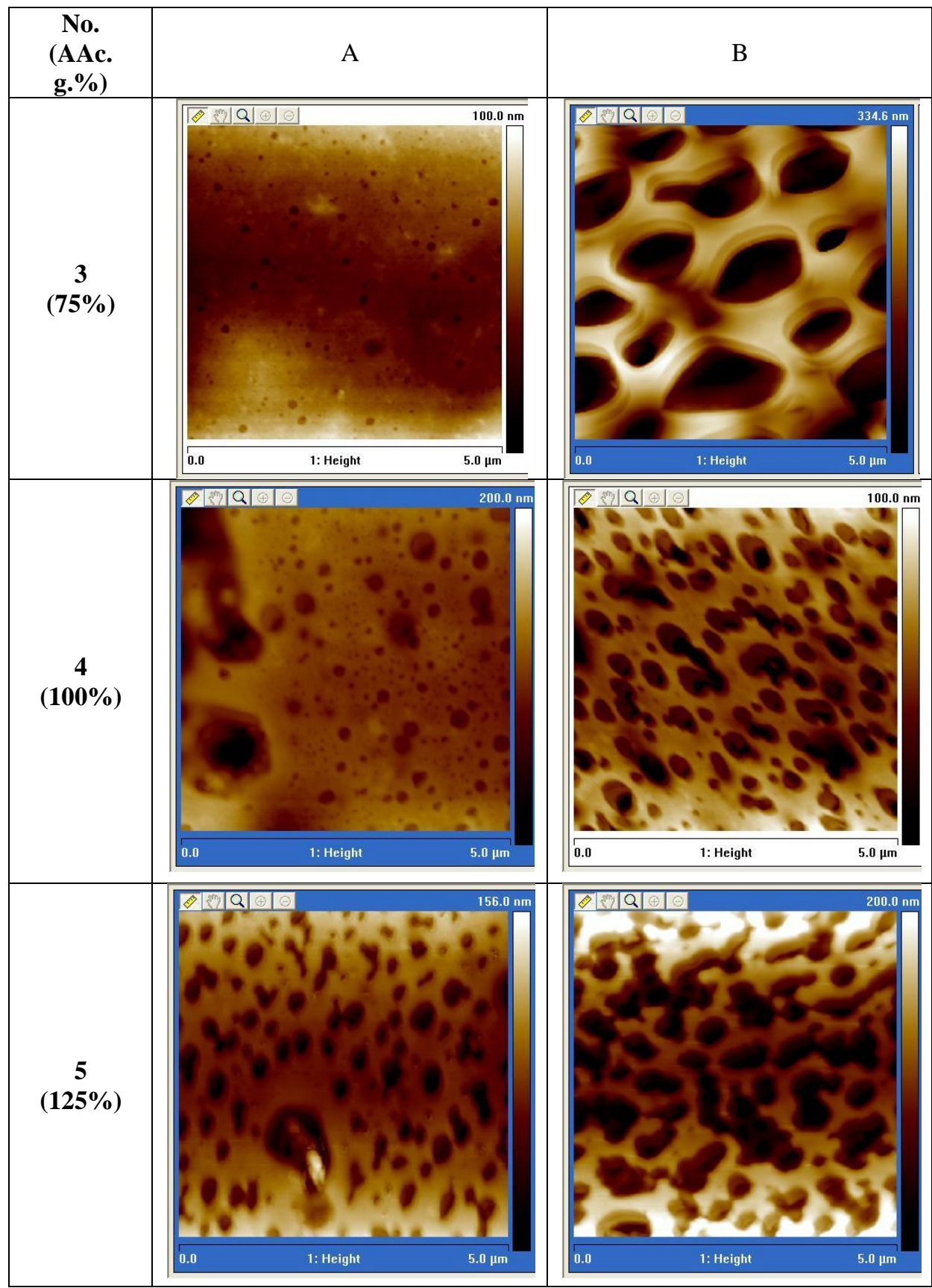

Fig. 2: AFM images of different AAc grafting (\%) CA \& PEG with $0.5 \% \mathrm{TiO}_{2}$ doped synthetic membranes (A) top and (B) bottom surface.

Table 5: Effect of AAc grafting (\%) on the pore analysis of membrane surfaces.

\begin{tabular}{||c||c|c||c|c||c|c||}
\hline \multirow{2}{*}{ Pore analysis } & \multicolumn{2}{c||}{ Membrane 3 } & \multicolumn{2}{c||}{ Membrane 4 } & \multicolumn{2}{c|}{ Membrane 5 } \\
\cline { 2 - 7 } & Top & bottom & Top & bottom & Top & bottom \\
\hline Area coverage (\%) & 34.52 & 80.93 & 17.21 & 28.6 & 97.3 & 42.53 \\
\hline Min. pore diameter $(\mathrm{nm})$ & 76.94 & 44.42 & 44.42 & 44.42 & 88.84 & 88.84 \\
\hline Max. pore diameter $(\mathrm{nm})$ & 1020.7 & 4694 & 430.7 & 516.16 & 5500 & 961 \\
\hline total area of pores $\left(\mathrm{nm}^{2}\right)$ & 22986 & 24712 & 25391 & 35422 & 36692 & 32623 \\
\hline Mean pore diameter $(\mathrm{nm})$ & 323.75 & 211.2 & 177.5 & 214.6 & 223.73 & 307.7 \\
\hline std & 230.53 & 433.0 & 86.27 & 100.0 & 421.49 & 188 \\
\hline Pore count & 71 & 117 & 143 & 165 & 164 & 106 \\
\hline
\end{tabular}


Table 6: Effect of AAc grafting (\%) on the grain analysis of membrane surfaces.

\begin{tabular}{||c||c|c||c|c||c|c||}
\hline \multirow{2}{*}{\multicolumn{1}{|c||}{ Grain analysis }} & \multicolumn{2}{c||}{ Membrane 3 } & \multicolumn{2}{c||}{ Membrane 4 } & \multicolumn{2}{c||}{ Membrane 5 } \\
\cline { 2 - 7 } & Top & bottom & Top & bottom & Top & bottom \\
\hline Area coverage $(\%)$ & 19.067 & 65.47 & 82.78 & 71.39 & 2.69 & 57.46 \\
\hline Min. grain diameter $(\mathrm{nm})$ & 44.42 & 44.42 & 44.42 & 62.82 & 44.42 & 44.42 \\
\hline Max. grain diameter $(\mathrm{nm})$ & 465.9 & 4935 & 5012 & 4907.8 & 474.32 & 4506 \\
\hline total area of grains $\left(\mathrm{nm}^{2}\right)$ & 26838 & 9246 & 17595 & 17972 & 3793 & 11896 \\
\hline Mean grain diameter $(\mathrm{nm})$ & 195.9 & 486.6 & 319.9 & 230.4 & 180.64 & 424.87 \\
\hline std & 81.69 & 1090 & 662.7 & 572.8 & 96.69 & 827.74 \\
\hline Grain count & 137 & 19 & 55 & 78 & 21 & 28 \\
\hline
\end{tabular}

According to the top surface (dense layer) of the synthetic AAc grafted membranes, the AFM images show changes in the surface morphology that accompanied with an increase in both roughness parameters and surface porosity with increasing the AAc grafting from 75 to $125(\%)$; this result is in agreement with the previous work ${ }^{31}$.

Obviously, the $\mathrm{R}_{\mathrm{q}}$ value increases from 14.4 to $25.4 \mathrm{~nm}$, the surface porosity increases from 34.52 to $97.3(\%)$ and the pore count increases from 71 to 164 . A good correlation with the increase in roughness parameters values and the increase of permeate flux was observed. So, the increase in flux is due to the increase in roughness parameters. While, the increase in salt rejection can be explained according to the Donnan potential effect, where higher Donnan potential leads to an increase in salt rejection of the membrane ${ }^{29}$. It is expected that, by further increase in the AAc grafting (\%), higher than $125 \% \mathrm{AAc}$, the salt rejection may decrease with the increase in water flux.

On the contrary, both roughness parameters and surface porosity values of the bottom layer were decreased by increasing the AAc grafting from 75 to $125 \%$. The bottom layer surface had become denser skins as well as smoother surface. The $\mathrm{R}_{\mathrm{q}}$ value decreases from 83 to $19.6 \mathrm{~nm}$, the surface porosity decreases from 80.93 to $42.53(\%)$ and the pore count decreases from 117 to 106 . Also, the grain $\left(\mathrm{TiO}_{2}\right)$ distribution was affected by increasing the grafting of AAc from 75 to $125(\%)$, it is obvious that the grain count was high (137) in the top surface with low count in the bottom surface (19) at low AAc grafting $(75 \%)$, and by increasing the grafting up to $125 \%$, the grain count decreases in the top surface (21) as compared with that in the bottom surface (28); this is due to the possibility of the increase of $\mathrm{TiO}_{2}$ aggregation increases.

These changes in both top and bottom surfaces morphology can be discussed on the basis of the viscosity and the concentration effects of the casting solution ${ }^{16}$. Considering a casting solution in a very dilute with volatile solvent, one can expected a formation of the concentration gradient between the top and the bottom surfaces immediately after spreading the casting solution on the casting plate; that is the polymer concentration in the solution-air interface (top surface) will be greater than that in the solution-glass interface (bottom surface), resulting in a high concentration of the precipitation centers in the top surface with lower porosity as compared to that in the bottom surface. On the other hand, and due to the low volatility of high concentration of the casting solutions as a result of the high concentration of AAc monomer, the concentration gradient between top and bottom surfaces will be low. Therefore, relatively similar morphologies with nearly the same porosity of the top and bottom surfaces were obtained.

\section{The effect of $\mathrm{TiO}_{2}$ doping:}

The grafting of AAc onto CA \& PEG copolymer has a positive effect on the properties of obtained CA \& PEGg-AAc/ $/ \mathrm{TiO}_{2}$ nanocomposite membranes because the carboxylic acid groups of AAc act as coordination sites for the titania phase ${ }^{32}$. $\mathrm{TiO}_{2}$ nanoparticles are connected with the functional groups of membrane by chemical bond formation, it react with carboxylic $(\mathrm{COOH})$ groups of acrylic acid. So, the probability of the $\mathrm{TiO}_{2}$ detached from the membrane matrix even under $\mathrm{RO}$ conditions is low. Experimentally; the high concentrations of doped $\mathrm{TiO}_{2}$ nanoparticles in the casting solution were not acceptable because it increases the possibility of $\mathrm{TiO}_{2}$ nanoparticles aggregation. So, the effect of $\mathrm{TiO}_{2}$ nanoparticles concentration was studied up to $1 \mathrm{wt}$. \%.

By studying the effect of $\mathrm{TiO}_{2}$ nanoparticles concentration composite on the surface features of the synthesized membranes, it is obvious that all the roughness parameters of both top and bottom surfaces increased. The $\mathrm{R}_{\mathrm{q}}$ value increased from 25.4 to $42.8 \mathrm{~nm}$ and from 19.6 to $283 \mathrm{~nm}$ for top and bottom surfaces, respectively.

On the other hand, the surface porosity and the pore count decreased; the surface porosity decreased from 97.3 to $9.74(\%)$ and from 42.53 to $41.65(\%)$ for top and bottom surfaces, respectively. Also, the pore count decreased from 164 to 52 and from 106 to 35 for top and bottom surfaces, respectively, as shown in Fig. (3); see Membrane No. 5 (Fig. 2) and Tables (7-9). 


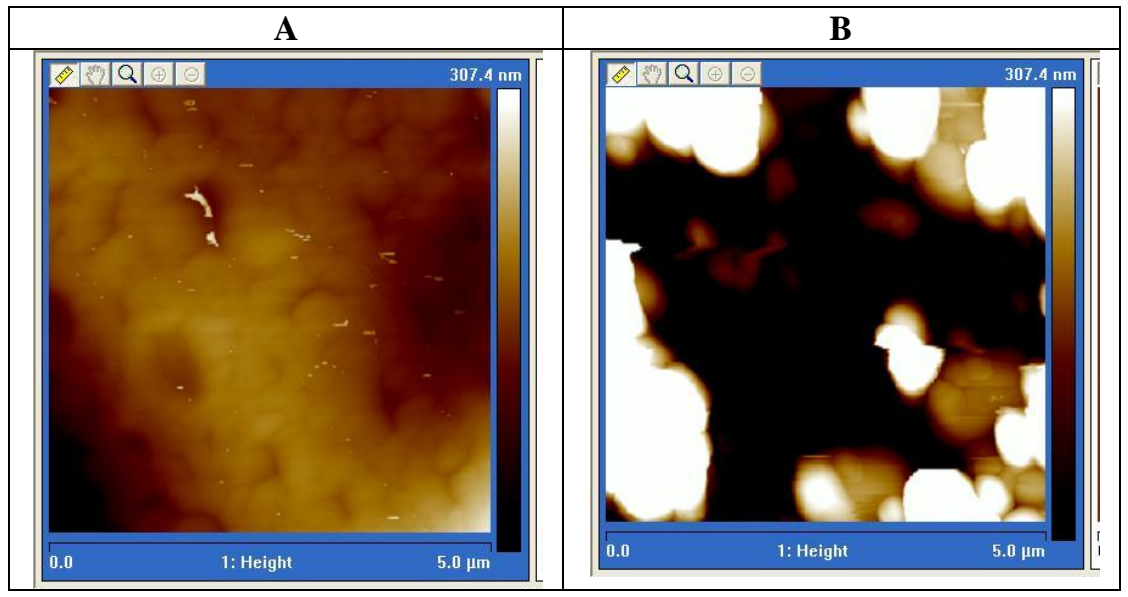

Fig. 3: AFM images of CA\&PEG-g-125\%AAc+1\% $\mathrm{TiO}_{2}$ synthetic membranes (A) top and (B) bottom surface.

Table 7: Effect of $\mathrm{TiO}_{2}$ nanoparticles concentration doping on the roughness parameters of the membrane surfaces.

\begin{tabular}{|c||c|c|c||c|c|c||}
\hline \multicolumn{1}{|c||}{$\begin{array}{c}\text { Membrane } \\
\text { No. }\end{array}$} & \multicolumn{3}{c||}{ Top Surface } & \multicolumn{3}{c|}{ Bottom surface } \\
\cline { 2 - 7 } & $\mathrm{R}_{\mathrm{q}}$ & $\mathrm{R}_{\mathrm{a}}$ & $\mathrm{R}_{\max }$ & $\mathrm{R}_{\mathrm{q}}$ & $\mathrm{R}_{\mathrm{a}}$ & $\mathrm{R}_{\max }$ \\
\hline $\mathbf{5}$ & 25.4 & 20.2 & 174 & 19.6 & 14.9 & 156 \\
\hline $\mathbf{6}$ & 42.8 & 32 & 351 & 283 & 235 & 1339 \\
\hline $\mathrm{R}_{\mathrm{q}}, \mathrm{R}_{\mathrm{a}}$ and $\mathrm{R}_{\max }$ unit is $\mathrm{nm}$ & \multicolumn{3}{|c|}{} & \multicolumn{3}{l|}{} \\
\hline
\end{tabular}

Table 8: Effect of $\mathrm{TiO}_{2}$ nanoparticles concentration doping on the pore analysis of the membrane surfaces.

\begin{tabular}{||c||c|c||c|c||}
\hline \multirow{2}{*}{\multicolumn{1}{|c||}{ Pore analysis }} & \multicolumn{2}{c||}{ Membrane 5 } & \multicolumn{2}{c|}{ Membrane 6 } \\
\cline { 2 - 5 } & Top & bottom & Top & bottom \\
\hline Area coverage $(\%)$ & 97.3 & 42.53 & 9.74 & 41.65 \\
\hline Min. pore diameter $(\mathrm{nm})$ & 88.84 & 88.84 & 44.42 & 44.42 \\
\hline Max. pore diameter $(\mathrm{nm})$ & 5500 & 961.04 & 518.07 & 4153 \\
\hline total area of pores & 36692 & 32623 & 11432 & 13159 \\
\hline Mean pore diameter $(\mathrm{nm})$ & 223.73 & 307.76 & 219.84 & 375.99 \\
\hline std & 421.49 & 188.05 & 111.88 & 685.63 \\
\hline Pore count & 164 & 106 & 52 & 35 \\
\hline
\end{tabular}

Table 9: Effect of $\mathrm{TiO}_{2}$ nanoparticles concentration doping on the grain analysis of the membrane surfaces.

\begin{tabular}{||c||c|c|c|c||}
\hline \multirow{2}{*}{\multicolumn{1}{|c||}{ Grain analysis }} & \multicolumn{2}{c|}{ Membrane 5 } & \multicolumn{2}{c|}{ Membrane 6 } \\
\cline { 2 - 5 } & Top & bottom & Top & bottom \\
\hline Area coverage $(\%)$ & 2.69 & 57.46 & 38.36 & 90.25 \\
\hline Min. grain diameter $(\mathrm{nm})$ & 44.424 & 44.42 & 44.42 & 44.42 \\
\hline Max. grain diameter $(\mathrm{nm})$ & 474.32 & 4506 & 1272 & 5187 \\
\hline total area of grains $\left(\mathrm{nm}^{2}\right)$ & 3793 & 11896 & 20416 & 17655 \\
\hline Mean grain diameter $(\mathrm{nm})$ & 180.64 & 424.87 & 443.84 & 280.24 \\
\hline std & 96.69 & 827.74 & 272.50 & 636.18 \\
\hline Grain count & 21 & 28 & 46 & 63 \\
\hline
\end{tabular}

The high water flux can be explained also on the basis that the surface of $\mathrm{TiO}_{2}$ was abundant and reacts with hydroxyl groups which could enhance the water flux of the membranes remarkably. Since $\mathrm{TiO}_{2}$ has high affinity to water, the membrane performance of solute transport can be improved. Also, for the grain analysis, it is obvious that in low $\mathrm{TiO}_{2}$ concentration, the $\mathrm{TiO}_{2}$ particles (grains) were regularly distributed; by increas- ing the doped $\mathrm{TiO}_{2}$ concentration, high concentration of $\mathrm{TiO}_{2}$ particles in the bottom layer was observed. This is due to the increase in the possibility of its aggregation which may be occur in high concentration and observed in the bottom surface of the membranes.

From all of the obtained results and according to high water flux and salt rejection (\%), CA \& PEG-g-125\% AAc+0.5 wt. $\% \mathrm{TiO}_{2}$ (membrane No. 5) can be consider- 
ed as the best synthetic membrane for water desalination process with expected high antifouling capability.

\section{Conclusion}

Blank and modified CA membranes were synthesized using the dry casting phase inversion method. From the results obtained in this study, the following conclusions can be derived:

1) PEG blending improves the properties of $C A$ membranes by the slight increase in the roughness parameters, but there is no any observed enhancement in RO performance due to the absence of active pores that corresponding to permeate flux.

2) The increase in AAc grafting (\%) increased both flux and salt rejection. The permeate flux increased due to increase the roughness. The increase in salt rejection $(\%)$ can be explained by Donnan effect.

3) The doping of $\mathrm{TiO}_{2}$ nanoparticles onto the CA \& PEG-g-AAc membrane matrix up to $1 \mathrm{wt} . \%$ increase the roughness parameters of both top and bottom surfaces of the synthesized membranes and in the same time; it decreased the surface porosity and pore count. It increased the permeate flux with neglectable effect on salt rejection.

4) Membrane No. 5 can be considered as the best synthetic RO membrane for water desalination of brackish and saline water, it possesses high flux and salt rejection with expected high antifouling capability.

\section{Acknowledgements}

The authors wish to thank Prof. Dr. Magdy Hosny ElSayed (Department of Hydro-geochemistry, Desert Research Center) for his continuous assistance and his advices during all work steps.

\section{References}

1) Loeb S. and Sourirajan S. (1962). "Sea water demineralization by mean of an osmotic membrane", Advan. Chem. Ser., 38: 117.

2) Khulbe K. C., Matsuura T., Lamarche G., Lamarche A. M., Choi, C. and Noh S. H. (2001). "Study of the structure of asymmetric cellulose acetate membranes for reverse osmosis using electron spin resonance (ESR) method". Polymer, vol. 42: 64796484.

3) Hirose M., Ito H. and Kamiyama Y. (1996). "Effect of Skin layer surface structures on the flux behaviour of RO membranes", J. of Membr. Sci., 121: 209-215.

4) Khulbe K. C., Kruczek B., Chowdhury G., Gagne S., Matsuura T. and Verma, S. P. (1996). "Characterization of membranes prepared from PPO by Raman scattering and atomic force microscopy" J. of Membr. Sci., 111: 57-70.

5) Stamatialis D. F., Dias C. R. and de Pinho M. N. (1999). "Atomic force microscopy of dense and asymmetric cellulose-based membranes" J. of Membr. Sci. 160: 235-242.

6) Cao X., Ma J., Shi X. and Ren Z. (2006). "Effect of
$\mathrm{TiO}_{2}$ nanoparticle size on the performance of PVDF membrane", Applied Surface Science 253: 20032010.

7) Bottino A., Cappannelli G., Monticelli O. and Piaggio, P. (2000). "Poly (vinylidenefluoride) with improved fictionalization for membrane production" J. Membr. Sci. 166: 23-29.

8) Bottino A., Cappannelli D Asti, V. and Piaggio P. (2001). "Preparation and properties of novel organicinorganic porous membranes" Sep. Purif. Technol. 22/23: 269-275.

9) Hester J. F., Olugebefola S. C. and Mayers A. M. (2002). "Preparation of $\mathrm{pH}$-responsive polymer membranes by self-organization" J. Membr. Sci. 208: 375-388.

10) Wang Z., Lu Y. W. and Wang S. M. (2002). "Study on the preparation and characteristics of PVDF/CA blend ultra filtration membrane" J. Membr. Sci. Technol. 22 (6): 4-8.

11) Li Y. and Lu X. L. (2001). "Research progress of modification of poly (vinylidene fluoride) porous membrane" J. Tianjin Poly tech. Univ. 20 (5): 74-78.

12) Bae T. H. and Tak T. M. (2005). "Effect of $\mathrm{TiO}_{2}$ nanoparticles on fouling mitigation of ultra filtration membranes for activated sludge filtration" J. Membr. Sci. 249: 1-8.

13) Kim S. H., Kwak S. Y., Sohn B. H. and Park T. H. (2003). "Design of $\mathrm{TiO}_{2}$ nanoparticle self-assembled aromatic polyamide thin-film-composite (TFC) membrane as an approach to solve biofouling problem" J. Membr. Sci. 211: 157-165.

14) Li J. S., Liang Y., Wang H. Y., Sun X. Y. and Wang L. J. (2004). "Preparation and characterization of $\mathrm{TiO}_{2} / \mathrm{PVDF}$ composite hollow fiber membrane" ACTA Polym. 5: 709-712.

15) Jiayan C., Shuchun B., Xingda Z. and Lingying Z. (1980). "Morphology of aromatic polyamide type asymmetric reverse osmosis membranes" Desalination, 34: 97-112.

16) Bowen W. R., Hilal N., Lovitt R. W. and Wright C. J. (1998). "A new technique for membrane characterization: direct measurement of the force of adhesion of a single particle using an atomic force microscope" J. of Membr. Sci., 139: 269-274.

17) Bowen W. R., Hilal N., Lovitt R. W. and William P. M. (1996). "Atomic force microscope studies of membranes: Surface pore structures of Cyclo pore and Ano pore membranes" J. of Membrane Sci., 110: 233-238.

18) Hansma P. K., Elings V. B., Marti O., and Bracker C. E. (1988). "Scanning tunneling microscopy and atomic force microscopy: Applications to Biology and Technology" Science, 242: 209-216.

19) Bowen W. R., Hilal N., Lovitt R. W. and William P. M. (1996). "Visualization of an ultra filtration membrane by non-contact atomic force microscopy at single pore resolution" J. Membr. Sci. 110: 229232.

20) Bowen W. R., Hilal N., Lovitt R. W., Sharif A. O. and William P. M. (1997). "Atomic force microsco- 
pe studies of membrane: Force measurement and imaging in electrolyte solutions" J. Membr. Sci. 126: 77-89.

21) Fritzsche A. K., Arevalo A. R., Moore M. D., Elings V. B., Kjoller K. and Wu C. M. (1992). "The surface structure and morphology of polyvinylidene fluoride microfiltration membranes by atomic force microscopy", J. Membr. Sci. 68: 65-78.

22) Bessieres A., Meireles M., Coratger R., Beauvillain J. and Sanchez V. (1996). "Investigations of surface properties of polymeric membranes by near field microscopy" J. Membr. Sci. 109: 271-284.

23) Lonsdal H. K., Merten V. and Riley R. L. (1965). "Transport properties of cellulose acetate osmosis membrane" J. Appl. Polym. Sci., vol. 9: 1341-1362.

24) Seung- Yeop K., Min-Oh, Y., Il Juhn, R., Dong Y. K. and Jae-Jin K. (1997). "Correlations of chemical structure, atomic force microscopy (AFM) morphology, and reverse osmosis (RO) characteristics in aromatic polyester high-flux RO membranes" J. Membr. Sci., 132: 183-191.

25) Jong A. Y. (1988). "Chemical initiated-grafted Nylon 4 membranes" J. Appl. Polym. Sci., vol. 36: 87-103.

26) Ramani M. P. S. and Ramachandhran, V. (1993). "Synthesis and study of RO performance of aromatic polyamide hydrazide membrane" Desalination, 90: 31-40.

27) Kesting R. E. (1990). "The four tiers of structure in integrally skinned phase inversion membranes and their relevance to the various separation regimes" J. Appl. Polym. Sci., 41: 2739.

28) Meier M. M., Kanis A. L. and Soldi, V. (2004). "Characterization and drug permeation profiles of micro porous and dense cellulose acetate membranes: influence of plasticizer and pore formation agent". Inter. J. of Pharmaceutics, vol. 278: 99-110.

29) El-Sayed M. H., Hassan E. A. and El-Aassar A. M. (2008). "Synthesis and characterization of cellulose acetate grafted acrylic acid reverse osmosis membranes" Desert Inst. Bull., Egypt, 58: 1-34.

30) Kim M. S. and Lee S. J. (2004). "Characteristics of porous polycarbonate membrane with polyethylene glycol in supercritical $\mathrm{CO}_{2}$ and effect of its porosity on tearing stress" J. of Supercritical Fluids, vol. 31: 217-225.

31) Freger, V. Gilron, J. and Belfer S. (2002). "TFC polyamide membranes modified by grafting of hydrophilic polymers: an FT-IR/ AFM/ TEM study" J. of Membr. Sci., 209: 283-292.

32) Joen D. J., Kim M. J., and Kwak S. Y. (2006). "Effects of addition of $\mathrm{TiO}_{2}$ nanoparticles on mechanical properties and ionic conductivity of solvent-free polymer electrolytes based on porous $\mathrm{P}$ (VdF-HFP)/P (EO-EC) membranes" J. Power Sources. Vol 162: 1304-1311. 